\title{
Desenvolvimentos no estudo do urbano e do regional em países de língua portuguesa
}

CRAVIDÃO, Fernanda; FERNANDES, José Alberto Rio; VALENÇA, Márcio Moraes (Org.). Regional and urban developments in Portuguese-speaking countries. Nova Iorque: Nova Science Publishers, 2012. 473p.

José Alberto Rio Fernandes

Departamento de Geografia da Universidade do Porto, Portugal

\section{A necessidade de livros}

Nas ciências sociais, uma certa cultura (quase ditadura!) anglo-saxónica de valorização da competitividade tende a impor ao mundo científico o ritmo alucinante dos textos curtos e hiper-especializados, publicados nas revistas indexadas, os quais são vistos como os que mais (ou os únicos que?) podem promover o progresso do conhecimento. Tal é compreensível, convenhamos, já que a facilidade de acesso ao que se publica em qualquer parte não permite (como antes) uma simples incorporação/adaptação do que é a novidade noutra parte do mundo e que se faz chegar (adaptando, umas vezes melhor que outras) a determinado contexto (limitado a uma região, país ou língua), o que era quase sempre feito numa lógica de reprodução (adaptada, quando muito) do que diziam alguns, poucos, "mestres", tomados por referência e insanamente reproduzidos (ou reproduzidos no que que escrevia quem os lia). Isso era (ou será ainda?) verdade, sobretudo, nos países ditos mais periféricos (como Portugal, na Europa, e Brasil, face à Europa), onde algumas disciplinas, das ciências sociais e humanas, tendiam a venerar e reproduzir o que diziam alguns poucos.

Assim, porque cada vez mais de nós temos menos tempo de nos lermos e porque face ao acesso generalizado a milhares de autores e milhões de textos, é razoável que se distingam os textos (necessariamente curtos) pelo número das citações e pela revista onde são publicados, num contexto que se pretende aberto e transparente, em que a avaliação anônima é a regra, a referência a alguns autores apenas e a algumas das suas obras, é cada vez menos a regra.

Mas, no entanto, parecendo essencial para combater uma certa letargia e mediocridade autolegitimada e indisputada, mais copista que produtiva e capaz de 
produzir conhecimento, também é certo que este "mundo perfeito" de anonimato e de competição franca e aberta não existe. Por isso, tal como muitos têm alertado, a par da articulação nas redes mais inovadoras e produtivas, associada à investigação de vanguarda, faz falta a slow science e a possibilidade de escrever e ler mais longamente - com maior amplitude e profundidade também, desejavelmente - textos mais longos, seja de/por autores consagrados, seja por de/por aqueles que se iniciam na reflexão científica e não têm ainda para dar ao leitor resultados de investigação "de ponta" associados à (pretensa) descoberta de uma qualquer coisa.

\section{As razões de um livro}

Regional and urban developments in portuguese-speaking countries [disponível em www.novapublishers.com] é um livro-coletânea, situando-se a meio caminho entre a ciência mais calma e a revista científica, em que se reúnem textos relativamente curtos e de enfoque especializado, sujeitos à arbitragem científica, os quais pretendem contribuir para o debate, mais do que dar conta do resultado de investigação, ainda que tal ocorra em alguns dos textos.

Trata-se de uma obra centrada no mundo que fala português (ou na parte do mundo que o faz), ainda que tenha a preocupação da sua divulgação global, donde o recurso ao inglês, como língua de expressão, no que pode ser tido como uma contradição, mas pode também ser visto como a melhor forma de promover internacionalmente a reflexão científica feita a propósito de Brasil e Portugal.

O livro resulta do esforço conjunto de dois grupos de pesquisa, o CEGOT, Centro de Estudos de Geografia e Ordenamento do Território (das universidades de Porto, Coimbra e Minho) e o NAPP-DPP, Núcleo Avançado de Políticas Públicas (do Departamento de Políticas Públicas da Universidade Federal do Rio Grande do Norte), ainda que o contributo venha de autores de várias instituições e disciplinas científicas, com perspectivas e preocupações diversas. Em comum parecem todos eles partilhar, com os organizadores, a ideia de que uma parte do passado comum e vínculos culturais mais ou menos profundos (linguísticos, desde logo) constitui uma vantagem para a aprendizagem partilhada, sem complexos, reconhecendo em Portugal, desde o Brasil, uma possibilidade de articulação europeia alternativa a outros países, como França, Reino Unido e Espanha, enquanto os portugueses descobrem no Brasil um leque de autores rico e diversificado, constituindo alternativa (ou pelo menos orientação complementar) à cooperação com investigadores europeus e norte americanos, no quadro de internacionalização que hoje tem de ser vista como obrigatória.

Impresso em 2012, Regional and urban developments in portuguese-speaking countries é a segunda obra editada por Márcio Moraes Valença (Universidade Federal do Rio Grande do Norte), Fernanda Cravidão (Universidade de Coimbra) e José Alberto Rio Fernandes (Universidade do Porto), depois de Urban developments in Brazil and 
Portugal, também publicado em 2012, reunindo 22 textos de autores destes dois países, a saber: Ermínia Maricato; Pedro Fiori Arantes; Mariana Fix; João Cabral e José Crespo; Sofia Morgado; Maria Florésia Pessoas de Sousa e Silva e Paulo José Lisboa Nobre; Bárbara Barbosa Neves; Iana A. A. Rufino, Carlos de O. Galvão, Vajapeyam S. Srinivasan, Janiro C. Rêgo e José do Patrocínio T. Albuquerque; Rosa Moura e Clovis Ultramari; Andrea Medrado; Ralfo Matos e Ricardo A. Garcia; Julia Richter; Antônio Tarcisio Reis e Maria Cristina Dias Lay; Miguel Sopas de Melo Bandeira; Saint-Clair Cordeiro da Trindade Júnior; Nicolas Bautès e Elodia Valette; Norberto Pinto dos Santos e Claudete Oliveira Moreira; Romulo Krafka e Yuri Kobukan; Roque Pinto; Jesse Jamba Wheeler; Luciana Pontes Pinto e Guilherme Azevedo.

\section{A organização do livro}

O tema desta coletânea é o desenvolvimento regional e urbano. Contudo, no seu título e no das quatro partes em que se organiza, existe um segundo sentido, já que, a propósito do desenvolvimento de base territorial, se procura dar conta também dos desenvolvimentos que ocorrem no estudo do urbano e do regional, não apenas em dimensões teóricas e metodológicas, mas ainda pelos contributos que a generalidade dos textos aporta para o conhecimento de regiões e lugares de Brasil e Portugal, por vezes em ligação a outros espaços da América do Sul ou do Sudoeste da Europa.

Os textos que foram selecionados pelos organizadores apresentam-se agrupados por temas, de acordo com a sua ligação mais direta ao desenvolvimento regional, à sustentabilidade, ao turismo e à história, considerando-se que os artigos assim agrupados dão conta de desenvolvimentos nos estudos regionais, da sustentabilidade, do turismo e da história de territórios diversos.

O primeiro tema reúne oito textos.

No primeiro destes, Iva Maria Miranda Pires aborda os investimentos espanhóis na Área Metropolitana de Lisboa e, a propósito das empresas espanholas, das suas estratégias e percepções, considera uma crescente integração de Lisboa num mercado ibérico único, o que contrasta com um passado ainda não muito distante, anterior à entrada na União Europeia, marcado por desconfianças e opções económicas diversas de ambos os lados da fronteira: com maior aposta na substituição de importações, no caso espanhol, e de maior abertura, no caso português.

O segundo texto é assinado por Ana Cláudia Duarte Cardoso e aborda o processo de urbanização na Amazónia, procurando evidenciar como a centralidade estruturada pelo tráfego fluvial ou pelo rodoviário gera uma certa organização regional e se repercute de forma diversa na expansão física de cada uma delas, o que obriga a articulações diferentes, em cada caso, entre política urbana e regional. 
Lorenzo López Trigal e José Somoza Medina abordam o Noroeste da Península Ibérica. Partindo do que é uma significativa continuidade física, do clima e relevo, especialmente, e da proximidade cultural que a história ajuda a entender, o texto explora a afirmação recente de algumas concentrações urbanas de Galiza (em Espanha) e do Norte de Portugal, salientando o preenchimento recente ao longo da faixa costeira, assim como o processo de difusão da urbanização (sobre uma matriz histórica de elevada densidade e grande quantidade de núcleos de povoamento), concluindo com reflexões a propósito de instrumentos de orientação ao planeamento territorial.

Elói Martins Senhoras e Claudete de Castro Silva Vitte abordam também um espaço regional transnacional, todavia de uma dimensão diferente. O texto considera a América do Sul a partir da distribuição dos recursos naturais e da sua relação com as infraestruturas regionais, de transporte, energia e telecomunicações, colocando em destaque a forma (relativamente despercebida) como se vai concretizando um plano (IIRSA) que favorece a articulação entre o Mercosul e a Comunidade Andina.

Paulo Ricardo da Rocha Araújo também aborda a América do Sul, em especial a "região econômica mundial" do Mercosul, centrando-se em questões de cooperação e conflito transfronteiriço, a propósito de alguns grandes investimentos previstos ou realizados e de estratégias de desenvolvimento regional, que colocam em causa conceitos como os de rural e urbano, assim como a relação Nação-Estado.

Júlia Maria Lourenço, Cristina Carvalho Danko, Luís Ramos e Delfim Fernandes abordam um espaço de menor dimensão, recorrendo a imagens de satélite para a compreensão das alterações no uso do solo, ocorridas nalguns municípios do Alto Douro entre 1990 e 2000, o que é feito com especial detalhe em Mesão Frio e Sabrosa, dando conta do reforço da especialização associada à vitivinicultura.

José Gilberto de Souza e José Jorge Gebara têm em consideração o Estado de São Paulo, colocando em destaque a dimensão política da fiscalidade e o modo como esta, pelo modo como é concebida no caso da taxa sobre a propriedade rural (ITR), pode contribuir para promover a evasão e a injustiça espacial.

Delfim Fernandes, Luis Ramos e Júlia Maria Lourenço, num segundo texto sobre questões associadas ao ordenamento e desenvolvimento territorial, dão conta, numa abordagem centrada em questões de natureza metodológica, das vantagens no recurso a um classificador baseado em redes neuronais, no caso, para avaliar os efeitos no processo de urbanização da implantação de uma rede viária de ligação rápida (IP4) no seu atravessamento pelo Município de Vila Real.

A segunda parte, agrupando textos mais preocupados com o desenvolvimento sustentável e os desenvolvimentos ocorridos no seu estudo, é a maior das quatro, reunindo nove textos, dos quais os três primeiros tratam a realidade portuguesa. 
O primeiro é assinado por Paula Cristina Remoaldo e Miguel Pazos Óton, em que se procura fazer a ligação entre sustentabilidade e mobilidade, realçando-se o forte investimento público realizado em rodovias, por contraponto à qualidade do serviço de transporte coletivo de pessoas, o que, como procuram demonstrar, teve efeitos negativos sobre o dia-a-dia da população e a sua saúde e bem-estar, como no caso (que estudam) dos municípios de Braga e Guimarães.

Elisabete Freire e J. L. Crespo, assim como Helena Nogueira, fazem incidir a sua reflexão mais a Sul, sobre a Área Metropolitana de Lisboa. Os primeiros abordam aspetos ligados ao uso do solo, dando conta de um processo de suburbanização e dispersão que coloca em causa a estabilidade do ecossistema e compromete solos agrícolas, além de ocorrer em parte em áreas de risco para pessoas e bens, o que leva a questionar o planeamento e as políticas de gestão territorial. O segundo texto questiona também o planeamento, defendendo um maior cuidado com a diminuição das desigualdades e a promoção da saúde, como consequência da relação que se estabelece entre condições socioeconômicas associadas aos lugares de residência e às diferenças da perceção face à saúde.

Já desde Brasil, Patricia Aulicino e Alex Kenya Abiko estabelecem uma ligação entre espaços de residência informal e desequilíbrios ambientais, partindo desta consideração, do estudo de alguns princípios, de elementos metodológicos e de alguns casos de intervenção, para a proposta do que acreditam poder constituir-se uma solução ambiental de "ecovila", em Vila Nova Esperança, na sua relação com a Fazenda Tizo Parque, junto ao rodoanel de São Paulo.

Niedja Lemos e Loreley Garcia abordam também a relação entre urbanização e espaço natural, dando conta de problemas sociais e ambientais que resultaram da expansão da cidade de João Pessoa junto ao Rio Jaguaribe.

Ana Maria de Souza Mello Bicalho e Scott William Hoefle procuram demonstrar como a consolidação de uma base industrial na cidade de Manaus e a expansão de comércio e serviços permitiu diversificar as fontes de rendimento, favorecendo um modelo de desenvolvimento rural alternativo à agricultura e pecuária extensivas, presentes na parte setentrional da Amazónia.

Reinaldo Antonio Petta, Cleyber Nascimento de Medeiros, Paulo Sérgio de Rezende Nascimento e Thomas F. Costa Campos trazem-nos a experiência da adoção de tecnologias de geoprocessamento no município de Parnamirim (no Nordeste do Brasil), procurando demonstrar como esta ferramenta de avaliação e de apoio à decisão política pode favorecer uma melhor articulação entre os interesses do desenvolvimento socioeconómico e a preservação e valorização de elementos naturais, numa área marcada por intenso crescimento.

Renata Osborne, Carlos Alberto Figueiredo da Silva e Sebastião Josué Votre procuram associar o desporto à educação para o desenvolvimento sustentável, dando conta das potencialidades de grandes eventos (como os Jogos PanAmericanos de 2007), da vantagem da prática desportiva em contexto natural e do 
papel que o desporto pode assumir no quadro das aprendizagens proporcionadas pela escola.

No último texto deste capítulo, Maria Conceição Barletta Scussel e Miguel Aloysio Satller procuram contribuir para a caracterização da sustentabilidade e qualidade de vida de algumas áreas residenciais de Porto Alegre, considerando para tanto a avaliação da perceção dos habitantes face à dimensão subjetiva da sustentabilidade.

Embora o tema possa ser referido nalguns outros, há três artigos que abordam especificamente questões ligadas à oferta e à prática turística, os quais são reunidos num terceiro conjunto.

O de Eugénio Wanderley Correia Dantas é de recorte teórico, discutindo as motivações do alargamento dos fluxos turísticos para destinos tropicais e defendendo que além das alterações simbólicas e sócio-tecnológicas nos países emissores, importará considerar as transformações ocorridas também nos lugares de destino.

O texto assinado por Mauro Lemuel Alexandre e Kátia Simone Santiago Teixeira acrescenta à preocupação teórica uma reflexão sobre o que se verifica nalguns lugares de grande procura na proximidade da cidade de Natal (Jenipabu e Pirangi do Norte), a propósito do papel do turismo nas suas relações com cultura e lugar, recusando as leituras mais simplistas e propondo uma maior preocupação com o planejamento.

O contributo assinado por Luisa Pinho, Helena Albuquerque e Filomena Martins sublinha também a importância do planeamento da atividade turística, mas tem um enfoque e uma inserção geográfica diferentes do anterior, já que, ao abordar o caso de Furadouro, no litoral do distrito de Aveiro, em Portugal, considera as evidências que apontam para o avanço do mar numa localidade onde cerca de $2 / 3$ das habitações são de segunda residência.

$\mathrm{Na}$ quarta e última parte, o tempo longo associa-se à compreensão da transformação do espaço, reunindo cinco textos, dos quais o primeiro, da autoria de Rui Paes Mendes, aborda a relação de Portugal com as colônias africanas e asiáticas, dando conta das mudanças ocorridas, especialmente, após a Independência do Brasil e, já no século XX, com o governo de Salazar, sem desvalorizar as hesitações entre o que chama de atitudes mais predatórias ou desenvolvimentistas, nem a importância dos contextos políticos nacionais e internacionais na política ultramarina.

Maria Angélica da Silva aborda o que considera ser a primeira idade da globalização (séculos XV e XVI), dando conta da diáspora das congregações franciscanas portuguesas no Brasil e da sua importância na valorização turística do legado, o que faz apelo a uma investigação (e porventura promoção) transnacional.

No seu texto, Rubenilson Frazão Teixeira procura, na dimensão geopolítica, a compreensão da extensão e coesão espacial do Brasil, dando conta, 
designadamente, do papel do Marquês de Pombal (séc. XVIII), bem como das ameaças de fragmentação do país no século XIX ou, ainda, dos desafios que se colocam na atualidade, em especial, na Amazónia, num contexto marcado pelo processo de globalização e por aparentes contradições políticas nacionais.

Fátima Martins Lopes regressa também ao século XVIII e ao desempenho de Sebastião José de Carvalho e Melo para explicar a rede urbana da Capitania do Rio Grande e o modo como esta parece resultar da tentativa de "civilizar" os nativos e urbanizar os seus povoados, de acordo com princípios de ordenamento do território que assentam em ruas, praças e prédios e dão lugar a espaços disciplinados que rompem com os padrões indígenas.

Por fim, Sandra Erickson e Glenn Erickson sublinham a importância da obra Os sertões (1902), de Euclides da Cunha (1866-1909), para a compreensão de um certo e especial tipo de pessoa, que Hegel teria esquecido. Este protótipo, personificado em Antônio Conselheiro, é retomado por Robert Bontine Cunningham Graham e depois lembrado por vários autores (entre os quais Borges e Vargas Llosa), os quais contribuem para que não fique claro o que é um plágio e quem melhor retrata uma personagem que, desde Canudos, se opõe a normas europeias, como o sistema métrico, o casamento civil e os impostos.

\section{Desenvolvimento urbano e regional (e desenvolvimentos nos estudos do urbano e do regional)}

Será que Regional and urban developments in portuguese-speaking countries ajuda a compreender o que é desenvolvimento de base territorial (regional e urbano)? Será que ajuda a dar conta dos desenvolvimentos no estudo do desenvolvimento urbano e regional?

Desenvolvimento há muito que é uma "palavra mágica" que, como tantas outras, com o uso, foi perdendo precisão nos seus contornos, mesmo que não tenha perdido o seu encanto e muito menos pertinência. Nalguns casos confunde-se com riqueza, já que, por exemplo, quando falamos em países ou outros territórios mais ou menos desenvolvidos, alguns vemo-los assim desde o PIB per capita ou pelo poder de compra médio dos residentes, ou ainda por um certo controle do processo de globalização, o que desvaloriza as diferenças a outro nível escalar e oblitera a economia não fiscal (e todos sabemos como ela é importante, por exemplo, se compararmos a galinha do campo que comemos, mas que não entra no circuito econômico que compõe o PIB, ao desastre com o automóvel que nos obriga a comprar serviços de reparação que pagam imposto). As Nações Unidas relacionam o desenvolvimento humano também com as condições de saúde e ensino e não faltam as tentativas de construção de indicadores mais sofisticados e melhor adaptados a determinadas realidades, quase sempre associando desenvolvimento a qualidade de vida. Mas, todos sabemos como a avaliação do desenvolvimento será sempre algo de pessoal e estará sempre imbuído de uma 
relação cultural de perfeição impossível, o que ajuda a compreender que - como é por isso famoso - o Reino do Butão tenha adotado como elemento central de avaliação do desempenho político e do estado do país um indicador de felicidade e não de desenvolvimento, ao mesmo tempo que investigadores diversos, muitas vezes desde uma perspetiva ecológica e com um sentimento de uma certa nostalgia (quando não anacronismo), anunciam a sociedade do pósdesenvolvimento ou buscam uma melhor compreensão e orientação para a ação desde as perspetivas do etnodesenvolvimento e da capacitação.

Mas, se por um lado aceitamos a imperfeita avaliação - e comparação -, por outro lado teremos de recusar a relativização e recusa de todo o tipo de avaliação e comparação, porquanto tal objetivamente serve apenas a quem a diferença aproveita. Assim teremos - como aqui se pretende - de contribuir para uma melhor compreensão da injustiça espacial, o que pode e deve fomentar um planeamento e gestão dos territórios orientada para um "melhor" desenvolvimento.

É certo, como aqui se vê, que, em regra, quando pensamos em desenvolvimento territorial, transportamos conosco uma ideia de igualdade, ou de desvio face a essa igualdade, tendo muitas vezes por base desse objetivo de (impossível) igualdade um pretenso (e indesejável) equilíbrio total entre espaços diversos.

Nesta dimensão espacial, que praticamente todos os textos do livro tomam por central, é importante considerar as perspectivas sociais, econômicas e ambientais, a que se tem acrescentado nos documentos de política o realce aos processos de governação, planeamento e gestão, o qual, tal como os anteriores, merece a atenção por parte da generalidade dos autores de Regional and urban developments in portuguese-speaking countries. Ao fazê-lo, estes dão ainda conta dos desenvolvimentos que estão a ocorrer no estudo do desenvolvimento, se bem que o conjunto não pretenda ter caráter de amostra estatisticamente relevante. Ao fazê-lo, manifestam uma velha, mas agora muito revalorizada, preocupação com a geografia econômica, em vários contextos, assim como em vários tempos. Por outro lado, não apenas a dimensão regional, como a local, é considerada por muitos daqueles que se preocupam especialmente com a dimensão ambiental e de sustentabilidade (outra palavra mágica!) do desenvolvimento, dando conta de desenvolvimentos da investigação, de uma grande e rica diversidade metodológica, que passam pelo recurso a tecnologias sofisticadas, assim como pela perceção subjetiva de residentes.

Diversos na dimensão espacial e na perspetiva - também ideológica -, os textos revelam ainda maiores ou menores enfoques teóricos e metodológicos, saudandose que quase todos "desçam" também ao estudo dos lugares concretos, em abordagens empíricas a que não falta contextualização e que, como os demais, contribuem para compreender melhor o desenvolvimento, contribuindo também 
- ainda que muito pouco, é certo - para o desenvolvimento dos estudos sobre o desenvolvimento.

Endereço para correspondência:

José Alberto Rio Fernandes - jariofernandes@gmail.com

Via Panorâmica, s/n

4150-564 Porto, Portugal 